\title{
BMJ Global Health Gendered implications of the COVID-19 pandemic for policies and programmes in humanitarian settings
}

\author{
Sarah Fuhrman (D) ,' Anushka Kalyanpur, ${ }^{2}$ Susannah Friedman, ${ }^{1}$ \\ Nguyen Toan Tran (D) ${ }^{3}$
}

To cite: Fuhrman S, Kalyanpur A, Friedman S, et al. Gendered implications of the COVID-19 pandemic for policies and programmes in humanitarian settings. BMJ Global Health 2020;5:e002624. doi:10.1136/ bmjgh-2020-002624

Handling editor Seye Abimbola

Received 9 April 2020 Revised 30 April 2020 Accepted 1 May 2020

\section{Check for updates}

(C) Author(s) (or their employer(s)) 2020. Re-use permitted under CC BY-NC. No commercial re-use. See rights and permissions. Published by BMJ.

${ }^{1}$ Humanitarian Policy \& Practice, CARE USA, Washington, District of Columbia, USA

${ }^{2}$ Global Sexual Reproductive Health and Rights, CARE USA, Washington, DC, United States ${ }^{3}$ The Australian Centre for Public and Population Health Research, University of Technology Sydney, Sydney, New South Wales, Australia

Correspondence to

Sarah Fuhrman;

sarah.fuhrman@care.org

\section{INTRODUCTION}

First detected in China's Hubei Province in late 2019, the coronavirus disease 2019 (COVID-19) has spread rapidly, leading the WHO to declare a global pandemic on 11 March 2020. ${ }^{1}$ Initial data indicates that older persons and those with underlying medical conditions are most likely to suffer serious complications. $^{2}$

While COVID-19 could have a devastating impact in any context, the dangers of the pandemic will be magnified for the nearly 168 million people in need of humanitarian assistance and protection worldwide, not least because many reside in fragile settings with weak water and sanitation infrastructure and lack access to quality health services. ${ }^{3}$ Refugees and internally displaced persons (IDPs) living in densely populated camps and informal settlements are acutely vulnerable as overcrowding could exacerbate transmission. Restrictions on freedom of movement, imposed to contain COVID-19, can also harm populations on the move, hampering their access to safety and protective mechanisms.

Although evidence indicates that emergencies disproportionately affect women and girls, ${ }^{3}$ there is little research on the implications of public health emergencies on different groups, particularly women and girls. (While this paper focuses on women and girls in humanitarian settings, the analysis will generally apply to other vulnerable groups-including the lesbian, gay, bisexual, transgender, queer/questioning, intersex, and asexual community and ethnic and racial minorities-and also to fragile contexts.) ${ }^{4}$ To address this gap, we analysed the potential gendered implications of the COVID-19 pandemic in humanitarian settings, drawing on research from past public health emergencies as well as our own experience. We examined policy and programmatic implications
Summary box

- Although preliminary analysis indicates that COVID-19 poses the highest risk to men, the elderIy, and those with comorbidities, available research on the gendered implications of past public health emergencies-such as that from the 2014-2016 West Africa Ebola outbreak-demonstrates that women and girls are disproportionately affected, particularly those who live in ongoing humanitarian crises.

- Our experience in previous humanitarian and public health emergencies indicated a need for practical, gender-sensitive recommendations for humanitarian practitioners that uphold the rights of affected populations. Consequently, we conducted a rapid analysis of the potential policy and programmatic implications of COVID-19 on women and girls.

- Our findings indicate that the pandemic will affect every aspect of the lives of women and girls. Their health will suffer, and they will have increased needs for protection, sanitation, shelter, education, food and livelihood support in the short term and long term.

- These findings informed recommendations that include: support women's and girls' leadership to ensure that COVID-19 prevention and control measures do not exacerbate harmful norms; bolster water, sanitation and hygiene services along with psychosocial support, essential health services, safe shelter and the provision of food, nutrition and hygiene commodities; prepare to respond to possible surges in gender-based violence and sexual exploitation and abuse; and ensure that vulnerable populations are included in national surveillance, preparedness and response plans and activities.

for key humanitarian sectors-including health; water, sanitation and hygiene; protection; shelter; education; food security and nutrition; and economic empowerment and well-being-with the aim of offering practical, gender-sensitive recommendations for humanitarian practitioners while recognising 
the unique needs and capabilities of women and girls in humanitarian settings.

\section{HEALTH}

Women and girls are exposed to multiple caregiving burdens that lead to greater physical and mental health risks. ${ }^{4}$ In many humanitarian contexts, they are responsible for household-level disease prevention and response efforts, which may place them at a higher risk of infection and of emotional, physical and socioeconomic harm. Women also often perform caregiving roles outside of the home; they comprise $70 \%$ of the health and social care workforce in many countries. ${ }^{5}$ This again increases the likelihood that they will be exposed to communicable diseases. In addition, social norms prevalent in many humanitarian settings dictate that women and girls are the last to receive medical attention when they become ill. ${ }^{6}$ These norms could prevent women and girls-particularly those who are already stigmatised, such as IDPs and refugees, members of certain ethnic or racial groups or those of different sexual orientationsfrom accessing testing and timely treatment for COVID19. Furthermore, testing may not be available for some displaced populations, as illustrated in Bangladesh, where testing facilities are limited to the capital, Dhaka, which is $400 \mathrm{~km}$ away from the world's largest refugee camp in Cox's Bazar. ${ }^{7}$

During past public health emergencies, resources were reallocated from routine healthcare services towards containing and responding to outbreaks, ${ }^{4}$ constraining access to essential healthcare, including mental health and psychosocial support and sexual, reproductive and maternal health services. Many of these services are already limited in humanitarian settings, particularly for some groups. For example, adolescent girls have unique sexual and reproductive needs that often go unmet, ${ }^{8}$ while non-citizens-including IDPs, migrants and refugees-may be unable to access government health systems. Others already suffering from diseases such as HIV, malaria and tuberculosis may find their treatment interrupted by these resource diversions at the same time that their pre-existing illnesses make them more susceptible to serious forms of COVID-19. ${ }^{9}$ It is likely that COVID-19 will exacerbate existing gaps and result in new ones, increasing women's and girls' vulnerability to COVID-19 as well as to other health conditions.

The COVID-19 pandemic could also increase the need for mental health and psychosocial support services just as resource diversions jeopardise them. This puts women and girls at risk, as frontline health workers-many of whom are female-women and girls with caregiving burdens, and community members fearful of becoming infected or infecting others may all experience stress and trauma relating to the outbreak. ${ }^{10}$

Fear of contracting Ebola led fewer women to attend health clinics during the 2014-2016 West Africa outbreak. ${ }^{4}$ Coupled with resource diversions from primary healthcare services and prevailing social norms, this led to a $75 \%$ increase in maternal mortality in three of the affected countries. ${ }^{4}$ A similar combination of factors during the COVID-19 pandemic could exacerbate other health conditions or delay COVID-19 treatment for women and girls in humanitarian settings.

\section{WATER, SANITATION AND HYGIENE}

In humanitarian settings, the COVID-19 pandemic may reduce women's and girls' access to hygiene and sanitary materials due to decreased household income, increased household competition for resources and disrupted supply chains. Women and girls who are reliant on humanitarian agencies for their water and sanitary suppliesincluding menstrual hygiene goods, soap and water treatment tabs-may find those services interrupted. Consequently, their ability to conduct household-level disease prevention efforts or to meet their own hygienic needs could be compromised. They may have to travel further to collect water and procure essential hygiene goods, making them more vulnerable to gender-based violence or sexual exploitation and abuse. ${ }^{11}$

\section{PROTECTION}

As illustrated above, health and humanitarian crises exacerbate gender inequalities and place women and girls at increased risk of gender-based violence and sexual exploitation and abuse. ${ }^{12}{ }^{13}$ For example, movement restrictions or quarantine measures to mitigate the COVID-19 pandemic in humanitarian settings may increase the incidence of intimate partner violence. ${ }^{14}$ Women and girls who are already stigmatised in their communities may be unjustly blamed for the spread of the disease. ${ }^{15}$ As the pandemic spreads, their access to medical and psychosocial services for survivors of harassment and violence could decrease as resources are reprioritised to fight COVID-19.

Children face additional protection risks in humanitarian settings if schools are closed: girls may have less access to health, hygiene and protection messaging and resources, and their caregiving burdens may increase. ${ }^{16}$ The negative economic impacts of public health emergencies may prompt families to resort to negative coping mechanisms, such as requiring girls to engage in transactional sex or arranging forced, early marriages. ${ }^{16}$ All children are at risk of becoming separated from their caregivers, who may be hospitalised or die. ${ }^{16}$

\section{SHELTER}

In humanitarian settings, female-headed households are nearly $30 \%$ more likely to have inadequate shelter than male-headed households. ${ }^{17}$ Inadequate shelter increases the risk of illness by $25 \%$ throughout a person's lifetime, while overcrowded shelter conditions can greatly increase the spread of infectious diseases. ${ }^{17}$ Past public health emergencies have also prompted populations to 
Box 1 Policy and programming recommendations to support women and girls in humanitarian settings during the COVID-19 pandemic

\section{For donors and policymakers}

- Bear in mind that the global COVID-19 response is only as strong as the weakest health system and provide immediate, flexible surge funding to ensure that operations in crisis settings can rapidly adapt and scale up.

- Require that all funding proposals contain adequate gender analyses and protection mainstreaming provisions.

- Ensure that aid and healthcare workers have access to all populations in need, including across borders, to accommodate surges in health personnel and allow the transport of humanitarian and medical supplies as needed for preparedness and response activities.

- Ensure that any COVID-19-related movement restrictions account for the different needs of vulnerable groups.

- Maintain compliance with international legal obligations, including the right to seek asylum.

- In the long term, ensure that emergency preparedness and response plans are grounded in sound gender analyses that consider gendered roles, risks, responsibilities and social norms and that account for the unique capabilities and needs of all vulnerable populations.

- In the long term, devote more resources towards researching the gendered implications of public health emergencies, especially disease outbreaks, so that public health preparedness and response plans can mitigate harm to women, girls and other vulnerable groups.

\section{Across all humanitarian sectors}

- Commit to proactive, early information sharing and coordination to ensure a robust response that uses intersectional analyses to account for the needs of all individuals, irrespective of age, disability, ethnicity, gender, migration status, nationality or sexual orientation. Ensure the full participation of at-risk populations, particularly women and girls.

- Partner equitably with trusted, locally relevant information channels to engage local communities and provide evidence-based information on COVID-19 for all populations while avoiding convening large groups.

- Bolster water, sanitation and hygiene services along with psychosocial support, essential primary and sexual and reproductive health servicesincluding adequate protective equipment, as defined in the Minimum Initial Service Package for Sexual and Reproductive Health in Humanitarian Settings - safe shelter, and the provision of food, nutrition and hygiene commodities, using cash and/or voucher assistance where feasible and using an inclusive and gender-sensitive lens while taking care to prevent and mitigate the spread of COVID-19.

- In the long term, work with local communities_-particularly women's groups_-before, during and after public health emergencies to provide the best possible services and ensure continued access and trust.

\section{Health and water, sanitation and hygiene}

- Involve female healthcare workers and local women leaders in decision making to rebuild their trust in health systems and cocreate COVID-19 responses that adequately address the needs of women, girls and other vulnerable groups in each community.

- Engage frontline health workers in community-based risk communication and disease surveillance to rapidly detect COVID-19. Disaggregate related data by sex, age and disability so that health experts can understand differences in exposure and treatment and tailor preventive measures.

- Implement responsive and inclusive approaches for COVID-19 outreach, information sharing and service delivery towards populations who may be less visible due to age, disability, gender or sexual orientation, immigration status, stigmatisation or other factors.

- Train and equip gender-balanced healthcare workers in COVID-19 infection prevention and control and clinical management. Ensure they are competent to identify gender-based violence risks and cases; handle disclosures in a compassionate, non-judgmental way; and know to whom they can refer patients for additional care.

- Ensure that menstrual hygiene, obstetric, reproductive and other primary healthcare commodities are well-stocked and available.

- Consider the effects of quarantine or social distancing measures on the physical and mental health needs of different populations.

- Where social distancing is not possible, work with local communities and authorities to explore localised solutions and emplace protective mechanisms, such as additional hygiene and sanitation support.

\section{Protection}

- Prepare for possible surges in gender-based violence and sexual exploitation and abuse affecting women, girls, people with different sexual orientations and other vulnerable populations. Support mobile hotlines to mitigate and respond to these risks where it can be done safely, understanding that not all women and girls will have access to phones.

- Plan for and mitigate the risk that pandemic response measures might result in unaccompanied or separated minors, including girls.

\section{Shelter}

- Ensure that gender analyses and the meaningful participation of asylum seekers, internally displaced persons and refugees, particularly women and girls, are fundamental considerations in national surveillance, preparedness and response plans and activities, including safer living and housing conditions to allow for social distancing.

\section{Education}

- Prepare and emplace plans to ensure the continuity of education, including via remote learning or radio broadcast.

\section{Economic empowerment and well-being}

Develop targeted economic empowerment strategies and/or explore cash transfer programming to mitigate the impact of the COVID-19 pandemic, including support for populations who are employed during the pandemic and lose their income once it is contained and for communities to recover from and build resilience against future shocks. 
migrate from rural to urban areas that were perceived to have more or better services, ${ }^{18}$ in turn leading to overcrowding, making social distancing impossible and increasing the risk of communicable disease transmission.

Given these considerations, IDPs and refugees, especially women and girls, who live in crowded camps or urban settings are at particular risk should COVID-19 reach humanitarian settings.

\section{EDUCATION}

As discussed under Protection, schools in many humanitarian contexts will likely close for an indefinite period to mitigate the spread of COVID-19. School closures can also have negative effects on displaced or refugee children for whom school can provide a reliable source of food and psychosocial support. For example, during the 2014-2016 West Africa Ebola outbreak, girls whose mothers were infected had to take on additional caregiving responsibilities. ${ }^{19}$ Even if their school was open, girls found it difficult to balance caregiving burdens with education. This led to increased absenteeism or to the girls leaving school completely, which had long-term effects on the girls' educational, economic and health outcomes. ${ }^{19}$

\section{FOOD SECURITY AND NUTRITION}

Public health emergencies can have tremendous impacts on food systems, including supply chains, which communities in humanitarian settings often rely on. In addition, movement restrictions and quarantine measures may result in less access to food, increasing prices at the same time that populations are less able to conduct economic activities and food production. Some households may resort to negative coping mechanisms, such as reducing food consumption, engaging in transactional sex, borrowing money or going into debt to pay for food. Surviving the declared end of an outbreak may not automatically ease food insecurity or malnutrition in affected communities, as it will likely take months to restart agricultural activities and trade.

The risk of heightened food insecurity and malnourishment during public health emergencies is particularly grave for women and girls because social norms in some humanitarian contexts dictate that they eat last and least. ${ }^{20}$ When food becomes scarce, women and girls-who are already more likely to be malnourished and suffer from anaemia than men and boys ${ }^{21}$ - could face additional health complications quickly, including increased susceptibility to COVID-19 or other infections, miscarriages and postpartum haemorrhage. ${ }^{22}$

\section{ECONOMIC EMPOWERMENT AND WELL-BEING}

Women living in humanitarian settings may be employed in informal, low-wage activities that are likely to be disrupted during the COVID-19 pandemic. During the 2014-2016 West Africa Ebola outbreak, restrictions on the movement of goods and people hampered women's trading activities and their ability to engage in agricultural activities, decreasing their earning potential. ${ }^{23}$ Concerns over spreading the infection, travel restrictions and xenophobia may limit the work opportunities of internally displaced or refugee women. ${ }^{24}$

Moreover, women's and girls' unpaid caregiving burdens will increase rapidly as governments close schools and care services to prevent the spread of COVID-19 and household members contract the disease. With already limited time-and likely employed at a lower wage, due to the global pay gap-women and girls will have even less self-directed time, including to spend on their own paid work. ${ }^{25}$ These factors, along with the potential loss of income due to the death of other household income earners, mean that the economic impact of COVID-19 on women and girls could be long-term and widespread.

\section{CONCLUSION}

To anticipate and address the potential challenges that the COVID-19 pandemic poses in humanitarian settings, box 1 lists priority considerations and recommendations for donors, policymakers and practitioners. Critical to mounting an effective COVID-19 response are understanding the implications of the pandemic on women and girls as well as working with them to design appropriate mitigation and response interventions. This can be actualised, for instance, by supporting women's and girls' leadership in health programming to ensure that COVID-19 prevention and control measures do not further exacerbate harmful gender inequalities and social norms; ensuring that all COVID-19-related funding proposals and data analyses consider age, sex and gender effects; and bolstering water, sanitation and hygiene services along with psychosocial support, essential sexual and reproductive health services ${ }^{26}$-including interventions to prevent and respond to gender-based violence, as defined in the Minimum Initial Service Package for Sexual and Reproductive Health in Humanitarian Settings—and providing safe shelter and food, nutrition and hygiene commodities.

Acknowledgements The authors are grateful to Dhabie Brown and Nick Tyre of CARE USA for their support throughout the research process.

Contributors SuF conceived the idea for the article. SaF is the guarantor. The article is based on a review of published material in the public domain and collective professional experience. All authors have extensive experience in developing, implementing and conducting research on policies and programmes on protection and sexual and reproductive health and rights in humanitarian settings. SaF is CARE USA's Humanitarian Policy Specialist. She holds a JD from the Thomas M. Cooley Law School and an LL.M. in Public International Law from University College London. AK is CARE USA's Team Lead for Sexual and Reproductive Health and Rights in Emergencies. She holds a Master in Public Health from Columbia University. SuF is CARE USA's Senior Director of Humanitarian Programming and Policy. She holds a Master of International Affairs in International Security Policy from Columbia University. NTT is an Adjunct Professor at the Australian Centre for Public and Population Health Research, University of Technology Sydney. He holds a medical degree from the University of Lausanne with Swiss board certification in internal medicine, a Master of Sciences from the London School of Hygiene and Tropical Medicine and a PhD in Demography from the University of Geneva. 
Funding The authors have not declared a specific grant for this research from any funding agency in the public, commercial or not-for-profit sectors.

Competing interests None declared.

Patient and public involvement statement This research was done without patient involvement. Patients were not invited to comment on the study design and were not consulted to develop patient relevant outcomes or interpret the results. Patients were not invited to contribute to the writing or editing of this document for readability or accuracy. Therefore, dissemination to patients or study participants is not applicable.

Patient consent for publication Not required.

Provenance and peer review Not commissioned; externally peer reviewed.

Data availability statement № additional data are available.

Open access This is an open access article distributed in accordance with the Creative Commons Attribution Non Commercial (CC BY-NC 4.0) license, which permits others to distribute, remix, adapt, build upon this work non-commercially, and license their derivative works on different terms, provided the original work is properly cited, appropriate credit is given, any changes made indicated, and the use is non-commercial. See: http://creativecommons.org/licenses/by-nc/4.0/.

\section{ORCID iDs}

Sarah Fuhrman http://orcid.org/0000-0002-2509-8302

Nguyen Toan Tran http://orcid.org/0000-0001-7134-7878

\section{REFERENCES}

1 World Health Organization. Who Director-General's opening remarks at the media briefing on COVID-19, 2020. Available: https://www. who.int/dg/speeches/detail/who-director-general-s-openingremarks-at-the-media-briefing-on-covid-19-11-march-2020

2 World Health Organization. Coronavirus disease 2019 (COVID-19) situation report - 98. who, 2020. Available: https://www.who.int/ docs/default-source/coronaviruse/situation-reports/20200427sitrep-98-covid-19.pdf?sfvrsn=90323472_4

3 United Nations. UN Global Humanitarian Overview 2020 - World, 2019. Available: https://reliefweb.int/sites/reliefweb.int/files/ resources/GHO-2020_v9.1.pdf

4 Davies SE, Bennett B. A gendered human rights analysis of Ebola and Zika: locating gender in global health emergencies. Int Aff 2016;92:1041-60.

5 Boniol M, Mclsaac M, Xu L, et al. Gender equity in the health workforce: analysis of 104 countries. who, 2019. Available: https:// apps.who.int/iris/bitstream/handle/10665/311314/WHO-HIS-HWFGender-WP1-2019.1-eng.pdf? sequence=1\&isAllowed=y

6 Beltrán Guzmán I, Gil Cuesta J, Trelles M, et al. Delays in arrival and treatment in emergency departments: women, children and nontrauma consultations the most at risk in humanitarian settings. PLOS One 2019;14:e0213362.

7 Vince G. The world's largest refugee camp prepares for covid-19. $B M J ; 220: 368$.

8 Inter-agency Working Group. Fact sheet: adolescent sexual and reproductive health needs in emergencies. IAWG adolescent health Sub-Working group, 2020. Available: https://iawg.rygn.io/resources/ adolescent-sexual-and-reproductive-health-needs-in-emergencies
9 Mallia P. Towards an ethical theory in disaster situations. Med Health Care Philos 2015;18:3-11.

10 World Health Organization. Mental health and psychosocial considerations during the COVID-19 outbreak, 18 March 2020. No. WHO/2019-nCoV/MentalHealth/2020.1, 2020

11 Sommer M, Ferron S, Cavill S, et al. Violence, gender and wash: spurring action on a complex, under-documented and sensitive topic. Environ Urban 2015;27:105-16.

12 O'Brien M, Tolosa MX. The effect of the 2014 West Africa Ebola virus disease epidemic on multi-level violence against women. Int $J$ Hum Rights Healthc 2016;9:151-60.

13 International Rescue Committee. Private violence, public concern: intimate partner violence in humanitarian settings. International rescue Committee, 2015. Available: https://www.rescue.org/ report/private-violence-public-concern-intimate-partner-violencehumanitarian-settings

14 Wanqing Z. Domestic violence cases surge during COVID-19 epidemic. sixth tone, 2020. Available: http://www.sixthtone.com/ news/1005253/domestic-violence-cases-surge-during-covid-19epidemic

15 Devakumar D, Shannon G, Bhopal SS, et al. Racism and discrimination in COVID-19 responses. Lancet 2020;395:1194.

16 The Alliance for Child Protection in Humanitarian Action. Protection of children during the COVID-19 pandemic. The alliance for child protection in humanitarian action, 2020. Available: https:// alliancecpha.org/en/series-of-child-protection-materials/protectionchildren-during-covid-19-pandemic

17 InterAction. The wider impacts of humanitarian shelter and settlements assistance, 2019. Available: https://www. humanitarianlibrary.org/resource/wider-impacts-humanitarianshelter-and-settlements-assistance-key-findings-report

18 ACAPS. Beyond a public health emergency: Potential secondary humanitarian impacts of a large-scale Ebola outbreak - Sierra Leone. ACAPS, 2016. Available: https://reliefweb.int/report/sierraleone/beyond-public-health-emergency-potential-secondaryhumanitarian-impacts-large

19 Kapur N. Gender analysis: prevention and response to Ebola virus disease in the Democratic Republic of Congo. care, 2020. Available: https://reliefweb.int/report/democratic-republic-congo/genderanalysis-prevention-and-response-ebola-virus-disease

20 UN World Food Program USA. Women are hungrier. un world food program USA, 2020. Available: https://wfpusa.org/women-arehungrier-infographic/

21 Ahmadi R, Ziaei S, Parsay S. Association between nutritional status with spontaneous abortion. Int J Fertil Steril 2017;10:337-42.

22 Jaleel R, Khan A. Severe anaemia and adverse pregnancy outcome. J surg Pak 2008;13:147-50.

23 UN Development Group Western and Central Africa,. "Socioeconomic impact of Ebola virus disease in west African countries," UNDG, 2015. Available: https://www.undp.org/content/dam/rba/ docs/Reports/ebola-west-africa.pdf

24 Wenham C, Smith J, Morgan R, et al. COVID-19: the gendered impacts of the outbreak. Lancet 2020:395:846-8.

25 UN Women, "Gender equality: women's rights in review 25 years after Beijing," UN Women, 2020. Available: https://www.unwomen. org/-/media/headquarters/attachments/sections/library/publications/ 2020/gender-equality-womens-rights-in-review-en.pdf?la=en\&vs= 934

26 Tran NT, Tappis H, Spilotros N, et al. Not a luxury: a call to maintain sexual and reproductive health in humanitarian and fragile settings during the COVID-19 pandemic. The Lancet Global Health 2020;21. 